\title{
0 desafio da formação permanente no fortalecimento das Redes de Atenção Psicossocial
}

\author{
Fernando Sfair Kinker(a) \\ Maria Inês Badaró Moreira(b) \\ Carla Bertuol(c)
}

\section{Introdução}

A educação permanente no âmbito do Sistema Único de Saúde (SUS) tem se colocado como um dos principais instrumentos para se alcançar a qualidade e a resolubilidade no cuidado em saúde. Transitando entre a construção e disseminação de tecnologias leve-duras e leves ${ }^{1}$, esses processos de qualificação têm sido muitas vezes avaliados de forma crítica por gestores, profissionais da rede e educadores, pois estes questionam se as versões mais conteudistas deixam de produzir transformações potentes nos atores envolvidos e em seus processos de trabalho. Ceccim e Feuerwerker ${ }^{2}$ defendem um desenho a partir do quadrilátero da formação para a área da saúde: ensino, gestão, atenção e controle social, ao mesmo tempo em que anunciam os desafios longínquos de tomá-los como direcionamento possível no âmbito dos serviços de saúde em função das demandas cotidianas ao trabalhador.

Observa-se, desde a promulgação do Decreto no 7.508/11 - que dispôs sobre a organização do SUS, o planejamento da saúde, a assistência à saúde e a articulação interfederativa ${ }^{3}$ - duas novas orientações para as práticas de saúde: a região e a Rede de Atenção à Saúde (RAS) e, nesse contexto, também a necessidade de viabilizar práticas pedagógicas que facilitem o aprendizado no universo do trabalho e que respeitem as singularidades dos municípios ${ }^{4}$.

Compreende-se, então, a importância de promover espaços de formação que permitam ao trabalhador avançar na construção de conhecimento por meio da experimentação e da transformação da prática cotidiana.

$\mathrm{Na}$ área da saúde mental, desde os anos 2000 , tem se intensificado os investimentos em educação permanente por meio de cursos ou do financiamento de supervisões clínico-institucionais, com o intuito de acompanhar e apoiar os trabalhadores na reflexão e na produção de sentido sobre a própria prática ${ }^{5}$.

Segundo o Ministério da Saúde ${ }^{5}$, as diferentes ações de formação e educação permanente no período de 2011-2015 tiveram entre seus objetivos a viabilização de um projeto de formação de trabalhadores para a consolidação do modelo de atenção em saúde mental territorial, a partir da troca, da reciprocidade e da integração entre diferentes núcleos de conhecimento em diferentes pontos da rede de atenção psicossocial.

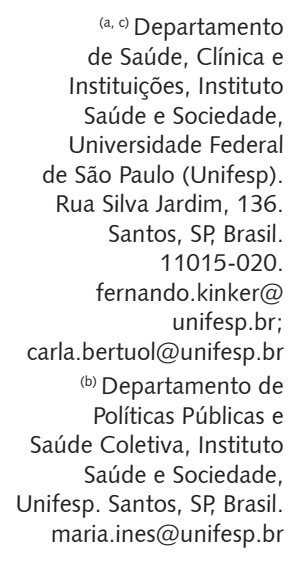

(a, c) Departamento de Saúde, Clínica e Instituições, Instituto

Saúde e Sociedade, Universidade Federal de São Paulo (Unifesp). Rua Silva Jardim, 136. Santos, SP, Brasil. 11015-020.

fernando.kinker@ unifesp.br; carla.bertuol@unifesp.br

(b) Departamento de Políticas Públicas e Saúde Coletiva, Instituto Saúde e Sociedade, Unifesp. Santos, SP, Brasil. maria.ines@unifesp.br 
Esse processo, vinculado ao fortalecimento da política nacional de saúde mental e à multiplicação de seus instrumentos reguladores e indutores, como as portarias e os editais, tem produzido inovações nos últimos anos. Uma dessas inovações foi a reorientação do financiamento dos processos formativos e de supervisão em projetos com escopo mais amplo, com condições de potencializar as transformações dos serviços, por meio do envolvimento e protagonismo de profissionais e usuários e da intensificação das trocas de experiências cotidianas de trabalho.

O projeto "Percursos Formativos na Rede de Atenção Psicossocial (RAPS)" foi lançado em 2013 pelo Ministério da Saúde ${ }^{5}$ buscando o fortalecimento das políticas municipais de saúde mental e dos preceitos da Reforma Psiquiátrica. Tem como premissas o intercâmbio profissional entre redes de atenção psicossocial dos municípios, o desenvolvimento e execução de planos de educação permanente e a circulação de saberes e experiências. Composto por redes preceptoras e redes visitantes, esse projeto ocorreu em diversos estados da Federação e possibilitou que cada município preceptor, escolhido entre aqueles com as redes mais desenvolvidas, recebesse profissionais de municípios diversos, sustentando experiências de acompanhamento cotidiano, de reconhecimento dos dispositivos da rede e de estudo e reflexão por meio da realização de oficinas temáticas.

Além disso, os municípios preceptores realizaram oficinas com profissionais e usuários das redes dos municípios visitantes, deslocando-se até esses municípios, como forma de multiplicar e ampliar o número de participantes. Houve intensa participação de profissionais e de usuários nos processos de formação, tanto na condição de professores quanto na de aprendizes, tendo-se como foco a troca de experiências.

Como forma de consolidar essa experiência inédita de formação permanente, em 2016 o Ministério da Saúde deu sequência à segunda fase do Projeto Percursos Formativos, instaurando o "Engrenagens dos Percursos Formativos". Esse projeto, que envolveu os mesmos municípios, consistiu na criação de ativadores de rede. Esses ativadores, um por município, orientados e acompanhados por um tutor, tiveram o papel de articular os vários pontos da RAPS por meio da instauração de processos formativos, da construção de projetos comuns entre os serviços e do fomento de uma produção coletiva em rede 5 .

O desafio de desenvolver novas estratégias e ações de formação permanente continua. Ademais, indica a necessidade de produzir rupturas epistemológicas nas formas de conceber o sofrimento psíquico e de produzir sentido no trabalho.

A produção de novos conceitos e práticas que direcionem a atenção psicossocial é um desafio cotidiano, necessário para o enfrentamento e desconstrução das formas que simplificam a experiência do sofrimento psíquico em códigos de doenças e, da mesma forma, a legitimação da desconstrução de dispositivos de contenção, controle e empobrecimento da vida.

Nesse sentido, também o Ministério da Saúde, ao lançar o Caderno de Atenção Básica no 34 com o tema Saúde Mental ${ }^{6}$, propôs uma nova abordagem ao sofrimento, partindo do conceito de pessoa e da convergência da Saúde Mental com a Atenção Primária. Visando "superar as limitações da visão dualista do homem, a construção de um novo modelo dinâmico, complexo e não reducionista e a orientação para novas formas de prática na área da saúde"6 (p. 29), esse caderno problematiza a diferença entre sofrimento e doença, aproximando-se de contribuições como as do médico norteamericano Eric Casse $7^{7,8}$, além dos autores da psiquiatria democrática italiana.

Em busca de aprofundar esse debate, o objetivo deste artigo é apontar alguns desafios acerca da formação permanente no contexto da Reforma Psiquiátrica, em especial no que diz respeito à construção de um novo objeto e de novos sentidos para as práticas na saúde mental.

Para isso, utilizar-se-á como substrato para a reflexão a experiência do Curso de Aperfeiçoamento em Saúde Mental para a RAPS da Unifesp, desenvolvida entre agosto de 2015 e fevereiro de 2016, descrevendo e discutindo principalmente os aspectos teórico-conceituais. A proposição temática do curso, matéria deste artigo, seguiu um percurso em busca de inaugurar novos olhares e possibilitar novos encontros de trabalhadores da saúde com as pessoas em sofrimento psíquico. 


\section{O curso de Aperfeiçoamento em Saúde Mental}

As ofertas do curso de especialização em Saúde da Família e a intensificação do trabalho conjunto entre alguns municípios e o polo Universidade Aberta do SUS (Unasus) da Unifesp em torno dos projetos de educação permanente no ano de 2015 explicitaram demandas urgentes no que se refere à qualificação e ao desenvolvimento de ações de saúde mental na Atenção Primária. Persistia a necessidade de intensificar o trabalho nos territórios para consolidar e alimentar a formação da RAPS, conforme a portaria 3.088 de 2011, que tem como importante componente a Atenção Primária9.

A partir dessa demanda, iniciaram-se discussões entre a coordenação do Curso de Aperfeiçoamento em Saúde Mental e os representantes da educação permanente e dos Programas de Saúde Mental dos municípios de Santos, São Bernardo do Campo, Mauá, Sorocaba e Guarulhos, com o intuito de organizar um curso que fizesse frente a vários desafios colocados às redes desses municípios.

A necessidade dos municípios era fortalecer as ações na Atenção Primária e intensificar o trabalho em rede, pois este implica processos formativos e de educação por meio do aprendizado e de construções de ferramentas de ação, como o desenvolvimento de práticas coletivas envolvendo os atores dos diversos serviços de saúde. Sendo assim, a proposta desse curso era envolver os profissionais que desenvolvem seu trabalho na Atenção Primária e nos serviços da RAPS, no processo de educação permanente, de forma a construir uma plataforma comum de conhecimentos e de práticas.

A construção desse projeto contou com o desenvolvimento de uma linha temática que percorreu princípios, estratégias e ferramentas da atenção psicossocial, discutindo de forma transversal questões relacionadas à realidade dos adultos, crianças e adolescentes com sofrimento psíquico e das pessoas com necessidades decorrentes do uso de álcool e drogas.

O curso foi oferecido a duzentos profissionais de nível superior dos serviços de saúde dos municípios. Os alunos foram selecionados e indicados pelos gestores das secretarias municipais de saúde. Inicialmente, o curso previa uma metodologia de ensino a distância com acompanhamento e mediação de tutores selecionados por meio do edital da Unasus/Unifesp.

Em modalidade de aperfeiçoamento, esse curso teve duração de 180 horas, divididas em seis módulos de trinta horas. Os duzentos alunos foram subdivididos em turmas de vinte alunos acompanhados por tutores, na proporção de um tutor para vinte alunos. Cada um dos cinco municípios apresentou quarenta profissionais de diferentes pontos da RAPS para realização do curso, em uma organização final de dois grupos de vinte alunos em cada município.

Ao longo do curso, ocorreram três encontros presenciais gerais, com todos os alunos e tutores, em momentos em que foram realizadas conferências com professores convidados e encontros de cada grupo de alunos com seus tutores.

Paralelamente à formação em sistema Educação a Distância (EAD), construiu-se junto com os trabalhadores do município um plano de ação coletivo realizado a partir de demandas do cotidiano do próprio serviço de origem dos alunos, contando com o apoio de um trabalhador local. Para isso, cada grupo de vinte alunos e seu apoiador se reuniam mensalmente em seu território.

O plano de ação nos territórios foi construído e executado paulatinamente a partir das tarefas finais de cada um dos módulos desse curso e esteve alinhado aos objetivos dessa proposta. Esse plano representou um importante dispositivo de mobilização do trabalho em rede, a partir das ações realizadas no próprio cotidiano do serviço em que estiveram em foco os temas debatidos no formato EAD.

É importante destacar que os apoiadores locais trabalharam em sintonia com os temas debatidos pelos tutores EAD. Tanto apoiadores quanto tutores tiveram encontros presenciais com a coordenação do curso no treinamento inicial de alinhamento e preparação; e encontros presenciais de avaliação e planejamento do trabalho no decorrer do curso, assim como participaram das conferências-encontros presenciais gerais do curso. 


\section{Percursos temáticos seguidos pelo curso}

Para alcançar o objetivo de inaugurar novos olhares e produzir encontros transformadores entre profissionais e usuários, foram utilizados alguns textos encomendados a autores que tinham uma importante trajetória na Reforma Psiquiátrica e na Saúde Coletiva. Iniciou-se a trajetória do curso com o capítulo 2 do Cadernos de Atenção Básica - "A definição de cuidado, sofrimento, pessoa e território"6 (p. 27-36) -, com uma apresentação de uma concepção própria de sofrimento, diferenciando-o da doença em si, já que as pessoas podem estar doentes e não sofrer, e sofrer e não estarem doentes. Foi problematizado que, apesar da doença, a vida, que é composta por diversas esferas e dimensões, pode ser vivida intensamente, de forma criativa e enriquecedora ${ }^{6}$. Além disso, os profissionais têm um papel importante na construção dessa possibilidade, uma vez que a sociedade Ihes dá o poder de interpretar, traduzir e definir o que se passa com as pessoas, o que poderá acontecer no futuro e do que as pessoas são ou não capazes.

Ao abordar e considerar na prática do cuidado as diversas esferas que compõem a vida das pessoas, pode-se seguir no sentido de encontrar caminhos que aumentem a potência de agir e conformem a autonomia das pessoas, entendendo que o trabalho com a autonomia é também o trabalho com a multiplicação das redes de dependência e com a possibilidade de produzir as próprias normas e formas de andar a vida, a partir das relações com as demais pessoas ${ }^{10}$. Essa inter-relação entre as possibilidades de agir e a ação das pessoas é o que as produz e, portanto, a dimensão das relações de poder é fundamental para a construção de si e do mundo.

Detectou-se a necessidade de reconhecer os limites dos paradigmas hegemônicos que sustentam a compreensão das ações de saúde mental a partir do reducionismo do sofrimento humano às nosologias e quadros de transtornos. Sendo assim, buscou-se analisar as consequências desse reducionismo operado nos processos de patologização de experiências de sofrimento ou de comportamentos desafiadores ou diferentes que fazem parte da condição humana e da vida cotidiana e que se referem a como as pessoas lidam com situações difíceis que a vida lhes traz ${ }^{11}$. Todas essas operações e codificações são sustentadas por ações de defesa dos territórios profissionais e de suas especialidades, que recortam os usuários da complexidade de suas necessidades, reproduzindo fragmentos de respostas que reproduzem o abandono.

Assim, a hiperespecialização pode produzir respostas pré-formadas que modulam as perguntas e as demandas, reforçando o lugar de saber dos especialistas e desautorizando qualquer saber que venha da parte dos usuários. Reforçou-se a necessidade de superar os filtros e repertórios que muitas vezes impedem que os profissionais enxerguem aspectos relevantes da experiência dos usuários que os procuram. Ponderou-se que os repertórios são importantes, mas devem ser colocados em seu devido lugar, para que se possa utilizá-los quando necessário e evitar que, ao contrário, sejamos sempre utilizados por eles, em uma relação de dominação.

A construção da possibilidade de lidar com a complexidade do sofrimento e das necessidades das pessoas nos levou a discutir no curso a noção de vínculo, de responsabilização e de trabalho focado no território e na realidade concreta de vida das pessoas. Em outras palavras, discutiu-se que a possibilidade de transformação do sofrimento e da vida ocorre quando mantemos certa cumplicidade e envolvimento com os usuários, estabelecendo contratos e sustentando uma presença consistente no cotidiano e no tempo ${ }^{12}$. O território aparece aqui como o lugar de vida dos usuários e como um organismo vivo, cheio de possibilidades e recursos que podem ser agenciados e acionados para a transformação de si e do próprio território. Território e coletivos de pessoas se autoconstroem reciprocamente, e essa é uma pista para se entender o sofrimento como algo que não está somente dentro do sujeito, mas nas próprias cenas que compõem o cotidiano.

Seguiu-se então em direção ao Projeto Terapêutico Singular (PTS) - que depois foi chamado de Projeto Terapêutico Compartilhado. Problematizou-se o PTS como uma construção complexa (para lidar com um fenômeno complexo), diferenciando-o, como ocorre frequentemente, do conjunto de procedimentos e ações que compõem a agenda dos serviços e dos usuários ${ }^{13}$. Desse modo, discutiu-se que o PTS é a construção de projetos de vida junto com os usuários e que esses projetos são móveis, 
ou seja, movem-se como os territórios e as cartografias dos oceanos, exigindo que se produzam caminhos e direções no próprio caminhar.

Nesse sentido, a construção do projeto terapêutico exige um olhar e uma escuta aguçada, dando atenção às diversas relações e aos diversos atores que compõem as cenas cotidianas de vida dos usuários, incluindo uma análise dos próprios serviços que compõem a RAPS. Dessa maneira, trabalhos mais fabris ou mais febris ${ }^{13}$ comporão os cenários dinâmicos da prática do cuidado, em permanente relação com os territórios de vida, já que os serviços sempre têm um papel importante na construção dos territórios.

Foi nessa direção também que se apresentou, a partir dos autores que foram convidados para elaborar os textos do curso, as quatro negações, ao discutir-se a gestão do cuidado. Foram elas: 1) a saúde não é só ausência de doenças; 2) o cuidado em saúde não pode ser realizado isoladamente; 3 ) não é possível pensar o cuidado em saúde sem considerar quem vai ser cuidado; e 4) não existe um trabalhador moral ${ }^{14}$. Assim, foram problematizadas as dimensões do trabalho em equipe, do trabalho em rede e da participação do usuário no cuidado de si e no lugar do trabalhador como aquele que também produz normas para si e para seu local de trabalho.

O cuidado foi apresentado como um processo delicado a ser composto com o usuário, construindo e tecendo novos mundos e novas realidades. A análise dos elementos para se pensar as múltiplas dimensões da gestão do cuidado, por meio da obra de Leon Tolstoi "A morte de Ivan Ilitch" ${ }^{15}$, foi exemplar no sentido de mostrar as peculiaridades e a delicadeza de um percurso terapêutico que considera e parte das necessidades dos usuários, compondo movimentos que transformam tanto a pessoa cuidada como o cuidador. Em seguida, discutiu-se e provocou-se os trabalhadores do SUS a olharem para suas próprias vidas e avalizarem formas de se enriquecerem no próprio ato do trabalho ${ }^{16}$.

Como aprofundamento dessas discussões, no último módulo do curso, resgataram-se os princípios e diretrizes atuais da Reforma Psiquiátrica, o protagonismo dos usuários, a reabilitação psicossocial e as políticas de saúde mental no campo da infância e adolescência. Retomou-se uma questão que poderia estar no primeiro módulo, mas que, propositadamente, optou-se por abordar no fim do último módulo, uma vez que se pretendeu, como foi feito, iniciar o curso aproximando-se o máximo possível da prática dos trabalhadores e do que seus corpos vivem diária e diretamente, sem mediações, no contato com os usuários.

Esses intentos, por certo, estavam imersos em algumas concepções acerca do objeto da Saúde Mental que pretendiam estimular uma ruptura epistemológica e que analisaremos a seguir.

\section{Um novo objeto para a Saúde Mental: ruptura epistemológica e construção de novos mundos}

A proposta temática do curso evidenciou uma tentativa de afetar os profissionais para que realizassem encontros transformadores com os usuários e para que se superasse a tendência a encaminhar aos especialistas qualquer situação de sofrimento. Além da maioria das questões de saúde envolver mudanças e representarem uma quebra no cotidiano existencial, o que, por si, implica a necessidade de os profissionais de saúde desenvolverem novas escutas e novos olhares para a existência dos usuários, há também uma ilusão de que os especialistas estão aptos a darem qualquer resposta, por serem considerados portadores de técnicas e saberes especiais.

Como apontado, ocorre muitas vezes que os especialistas, também dominados por seus especialismos, deixam de entrar em contato com a existência dos usuários, dialogando apenas com sinais e sintomas e com entidades mórbidas construídas pelas ideologias médico-psicológicas, mesmo que estas estejam pautadas por evidências.

Ao dialogar apenas com as entidades mórbidas, os profissionais e os usuários permanecem reféns de uma série de circunstâncias, movidas por relações concretas de poder nos territórios de vida e nos próprios consultórios (que também fazem parte desses territórios e dessas cenas), que não possibilitam metamorfoses, criação de novas formas de vida e novas relações, mas a manutenção de uma simplificação que empobrece o fenômeno e tudo o que ele tem de transformador. 
Se entendermos que o que caracteriza a vida é a constante transformação, entenderemos também que os processos de calcificação e endurecimento das relações terapêuticas produzirão apenas o enfraquecimento da vida e a morte. O papel terapêutico, aqui entendido como um catalisador de transformações na existência, só pode se dar em um constante recompor das cenas, que nunca serão iguais ao momento que passou.

O novo objeto da saúde mental, que os italianos nomearam "existência-sofrimento em relação com o corpo social" 17 , exige a imersão nas cenas que produzem relações de exclusão e invalidação das pessoas e de suas experiências.

Essa mudança de objeto exige e é em si uma ruptura epistemológica, uma nova relação de saber, interconectada e autoproduzida por mudanças nas relações de poder entre usuários e profissionais, usuários e instituições, usuários e territórios vivos, famílias, atores sociais múltiplos, culturas e valores. Isso porque entendemos o paradigma como algo que não se refere apenas ao campo do conhecimento, mas também ao campo da cultura, dos valores, da ideologia e das relações ${ }^{18}$.

\section{Ressonâncias da experiência}

As ressonâncias da experiência do curso puderam ser verificadas em algumas falas e postagens dos alunos nos fóruns de discussão. Em muitas dessas, os alunos explicitaram como foram afetados pelas discussões e pelas experiências práticas na construção local de projetos de intervenção.

Entre os elementos promotores de novos olhares, além de importantes reflexões teórico-conceituais, durante o curso, foi proposto que os alunos passassem um dia trabalhando no serviço do colega, como forma de vivenciar os diferentes pontos da rede. Desse modo, foi possível um mergulho no cotidiano da prática da atenção psicossocial, discutindo alguns dispositivos, ferramentas e situações que podem promover as transformações das cenas de exclusão e de sofrimento. Assim, partiu-se para o campo da associação intensa e quente com o território, seus recursos e seus atores, e propuseram-se algumas iniciativas que podem movimentar e multiplicar as trocas sociais, as experimentações, as afetações e os encontros transformadores de pessoas e de cenas. Essa experiência gerou muitas reflexões e trocas durante o processo.

A oferta e o desafio do trabalho conjunto de apoiadores, tutores e alunos no curso foi uma possibilidade concreta de atuação em rede, pois a efetivação das diretrizes e dos objetivos da RAPS e de um trabalho em rede não se dá pela somatória de pontos de atenção implantados, nem pelo elenco organizativo dos componentes ou, ainda, pela simples modernização do circuito assistencial. A RAPS se efetiva - isto é, só existe - na dependência de pessoas (de pontos de atenção diversos) que se conectam e se coordenam com uma finalidade comum. Assim, a RAPS tem duas dimensões: uma normativo-institucional, que afirma a unidade institucional da rede; e outra operacional, prática e concreta, que depende das relações efetivas entre as pessoas ${ }^{4}$ (p. 91-2).

Esses foram, talvez, os pontos mais importantes no desenvolvimento do curso: possibilitar que os profissionais de diversos pontos da RAPS pudessem entrar em contato com os usuários sem serem dominados por repertórios e protocolos; partir das necessidades apresentadas; tornar complexo o entendimento do sofrimento psíquico; e trabalhar em uma rede flexível, criativa e autodeformante, de forma a dialogar e coproduzir processos transformadores com os usuários.

Houve também grande aproximação de gestores que desenvolveram o papel de apoiadores ao cotidiano de trabalho dos outros profissionais por eles apoiados. Muitos foram os relatos, no decorrer do curso, afirmando que sentiam sua prática e envolvimento com o trabalho, com a equipe e com os usuários se transformando, e que novos paradigmas estavam se formando.

A respeito dos relatos sobre cenas que produzem situações de sofrimento e sobre a participação dos próprios profissionais e de seus saberes, valores e práticas nessas cenas, coproduzindo-as, a aluna do município A manifestou:

Têm pessoas cuja vida é ir à UBS [Unidade Básica de Saúde]. Como elas procuram um médico, a queixa acaba sendo clínica. O fato é que, em muitos casos, essas pessoas acabam fazendo uma série de exames que não indicam nada de anormal. Não é de médico (ou então de intervenção 
focada na queixa) que estas pessoas estão necessariamente precisando. Quando se faz uma abordagem mais ampla, entendendo o indivíduo no seu contexto familiar e comunitário, nós temos a possibilidade de dar a ela um atendimento e um acompanhamento melhor.

A aluna do município B reforçou:

Transformar o sofrimento implica enriquecer a vida das pessoas em todas as suas esferas. Isso vale tanto para os "loucos" como para aqueles que procuram a UBS com uma queixa vaga.

No que diz respeito à aproximação com os usuários e com os demais profissionais da rede, a aluna do município $C$ escreveu:

Por isso, minhas colegas, eu entendo que a desinstitucionalização começou agora dentro de cada um de nós a partir do momento que decidimos iniciar este curso, e percebo o quanto meu entendimento mudou. Hoje vejo que para transformar a realidade precisamos do outro e esse outro inclui não só os profissionais da RAPS, mas também o indivíduo que sofre, sua família, sua vizinhança, seu bairro, etc.

Foi ficando claro aos alunos que o grande desafio e o objeto de intervenção para os planos de ação era o fortalecimento e a constituição das redes. Nesse sentido, diz a aluna do município D:

Nessa perspectiva, a desinstitucionalização, além da desospitalização, propõe uma desconstrução da compreensão do sofrimento psíquico como doença, excluindo a ideia de necessidade de tutela ou internação, modificando as relações de saber/poder que estavam a serviço de um tipo de sociedade que não queria lidar com seus problemas, optando pelas redes de contenção da vida. Traz como desafio combater a exclusão e a violência, trazendo novas possibilidade de viver e reinventar a vida para todos os atores do processo, construindo um trabalho contínuo e sem fim.

Por fim, ficou evidente, no curso, a necessidade de um investimento permanente na construção coletiva das práticas e dos saberes de profissionais, nos usuários e nos gestores da RAPS, e não apenas nas iniciativas de aprendizagem isoladas e fragmentadas. É o próprio processo cotidiano de trabalho que deve ser enriquecido, "quente", por meio do protagonismo e envolvimento de todos os atores. Ou seja, o enriquecimento da prática exige uma construção e um envolvimento sem ponto final. É o que diz uma aluna do município E: "Esse curso foi muito potente. Não deixemos essa chama se apagar".

\section{Conclusão}

As produções de novos paradigmas, sempre em mutação, são importantes para se lidar e potencializar a riqueza da vida, aumentar a potência de agir e modificar todos os atores em jogo: usuários dos serviços, profissionais de saúde mental e atores dos territórios existenciais.

O objetivo principal do curso em questão, apoiando-se no material produzido sob encomenda a vários autores, foi problematizar o objeto da saúde mental, o que implica em mudanças nas práticas e nos saberes, entendendo que essa é uma aposta fundamental para o processo da Reforma Psiquiátrica no Brasil, uma vez que se pretende que a atenção psicossocial se diferencie das trajetórias excludentes e empobrecedoras da ciência positivista e cartesiana, que tanto influenciaram e simplificaram a história da Psiquiatria e que atravessam, mesmo que não percebamos, as nossas práticas cotidianas, seja nos serviços ou na universidade.

As transformações propostas exigem que novos mundos sejam produzidos. E essa era a proposta do curso: contribuir na produção de novos mundos e de novas redes, de forma a apostar em processos de formação permanente participativos, que valorizassem a prática cotidiana, integrassem profissionais, 
usuários, a realidade dos territórios e dos serviços e aproximassem os atores da gestão, tornando-a expandida e participativa. Apenas a vivência dessa ruptura epistemológica pode modificar a relação dos profissionais da atenção primária e da saúde mental com as pessoas que sofrem psiquicamente. Essas rupturas possibilitam o exercício de encontros transformadores, metamorfoses que se dão no aqui e agora da relação, e no ato de agenciar e multiplicar os atores em relação nos territórios de vida. Lidar de frente com a experiência do sofrimento leva necessariamente à construção de novas redes e novas alianças, agenciamentos que produzem novas redes de dependência e fortalecem a autonomia.

Essa opção explica porque não se iniciou o curso pelo caminho mais óbvio, que seria retomar o histórico da reforma, seus princípios, diretrizes e dispositivos. Ao contrário, optou-se por iniciar o curso problematizando a experiência cotidiana dos profissionais no encontro com as pessoas em sofrimento para abrir novos caminhos e, posteriormente, quando aqueles estivessem suficientemente mobilizados e envolvidos, iniciar, no fim do curso, a discussão sobre a Reforma Psiquiátrica e seus dispositivos.

O percurso do curso reforça a importância de manter espaços de produção de conhecimento em aberto para que se possa relatar experiências, colocá-las em análise e não deixar a chama se apagar.

\section{Contribuições dos autores}

Todos os autores participaram ativamente de todos os momentos da produção deste texto, desde sua concepção, discussão e revisão até sua aprovação final.

\section{Referências}

1. Merhy EE. O ato de cuidar: a alma dos serviços de saúde. In: Ministério da Saúde (BR). Secretaria de Gestão do Trabalho e da Educação na Saúde. Departamento de Gestão da Educação na Saúde. Ver - SUS Brasil: cadernos de textos. Brasília: Ministério da Saúde; 2004. p.108-37. (Série B. Textos Básicos de Saúde).

2. Ceccim RB, Feuerwerker L. O quadrilátero da formação para a área da saúde: ensino, gestão, atenção e controle social. Physis. 2004; 14(1):41-65.

3. Presidência da República (BR). Decreto n 7.508, de 28 de Novembro de 2011. Regulamenta a Lei no 8080, de 19 de Setembro de 1990, para dispor sobre a organização do Sistema Único de Saúde - SUS, o planejamento da saúde, assistência à saúde a articulação interfederativa, e dá outras providências [Internet]. Diário Oficial [da] República Federativa do Brasil. 2011 [citado 10 Ago 2016]. Disponível em: http://www. planalto.gov.br/ccivil_03/_ato2011-2014/2011/decreto/D7508.htm.

4. Assis JT, Barreiros CA, Jacinto ABM, Kinoshita RT, Macdowell PL, Mota TD, et al. Política de saúde mental no novo contexto do Sistema Único de Saúde: regiões e redes. Divulg Saude Debate [Internet]. 2014; 52:88-113 [citado 10 Ago 2016]. Disponível em: http:// cebes.org.br/site/wp-content/uploads/2014/12/Divulgacao-52.pdf.

5. Ministério da Saúde (BR). Secretaria de Atenção à Saúde. DAPES. Coordenação Geral de Saúde Mental, Álcool e Outras Drogas. Saúde mental no SUS: cuidado em liberdade, defesa de direitos e rede de atenção psicossocial. Relatório de gestão 2011-2015. Brasília: Ministério da Saúde; 2016. 
6. Ministério da Saúde (BR). Secretaria de Atenção à Saúde. Departamento de Atenção Básica. Saúde mental. Brasília: Ministério da Saúde; 2013. (Cadernos de Atenção Básica, n. 34).

7. Cassel EJ. The nature of suffering and the goals of Medicine. 2nd ed. New York: Oxford University Press; 2004.

8. Cassel EJ. Suffering and medicine. N Engl J Med. 1982; 306(11):639-45.

9. Ministério da Saúde (BR). Portaria n 3.088, de 23 de Dezembro de 2011. Republicada em 21 de maio de 2013. Institui a Rede de Atenção Psicossocial para pessoas com sofrimento ou transtorno mental e com necessidades decorrentes do uso de crack, álcool e outras drogas, no âmbito do Sistema Único de Saúde (SUS). Diário Oficial [da] República Federativa do Brasil [Internet]. 21 Maio 2013 [citado 10 Ago 2016]. Disponível em: http://bvsms.saude.gov.br/bvs/saudelegis/gm/2011/prt3088_23_12_2011_rep.html.

10. Kinoshita RT. Contratualidade e reabilitação psicossocial. In: Pitta A, organizador. Reabilitação psicossocial no Brasil. São Paulo: Hucitec; 1996.

11. Braga-Campos FC. Sofrimento e cuidado em saúde mental. Módulo 1. Curso de aperfeiçoamento em saúde mental [Internet]. São Paulo: UNASUS; 2015 [citado 3 Jul 2016]. Disponível em: https://ares.unasus.gov.br/acervo/bitstream/handle/ARES/3108/ M\% C3\% B3dulo\% 201\% 20SM.pdf?sequence $=1$.

12. Pinheiro S. Práticas de atenção psicossocial no território. Módulo 2. Curso de aperfeiçoamento em saúde mental [Internet]. São Paulo: UNASUS; 2015 [citado 3 Jul 2016]. Disponível em: https://ares.unasus.gov.br/acervo/bitstream/handle/ARES/3109/ M\% C3\%B3dulo\% 202\% 20SM.pdf?sequence=1.

13. Lancetti A. O projeto terapêutico singular e o trabalho de matriciamento. Módulo 3. Curso de aperfeiçoamento em saúde mental [Internet]. São Paulo: UNASUS; 2015 [citado 3 Jul 2016]. Disponível em: https://ares.unasus.gov.br/acervo/bitstream/handle/ ARES/3243/Mod\% C3\%BAlo\%203_SM.pdf?sequence $=1$.

14. Ceclílio LCO. O cuidado em saúde. Módulo 4. Curso de aperfeiçoamento em saúde mental [Internet]. São Paulo: UNASUS; 2015 [citado 3 Jul 2016]. Disponível em: https:// ares.unasus.gov.br/acervo/bitstream/handle/ARES/3244/M\% C3\% B3dulo\% 204\% 20SM. pdf? sequence $=1$ \&isAllowed $=y$.

15. Cecilio LCO. A morte de Ivan Ilyich, de Leon Tolstoi: elementos para se pensar as múltiplas dimensões do cuidado. Interface (Botucatu). 2009; 13(1):545-55.

16. Maximino VS, Liberman F, Jurdi APS, Brunello MIB. Dispositivo em atenção psicossocial. Módulo 5. Curso de aperfeiçoamento em saúde mental [Internet]. São Paulo: UNASUS; 2015 [citado 3 Jul 2016]. Disponível em: https://ares.unasus.gov.br/acervo/ bitstream/handle/ARES/3582/Modulo_5_SM.pdf?sequence=1.

17. Rotelli F. Desinstitucionalização. 2a ed. Nicácio F, tradutora. São Paulo: Hucitec; 2001.

18. Morin E. O método 4: as ideias - habitat, vida, costumes, organização. 4a ed. Silva JM, tradutor. Porto Alegre: Salina; 2005. 
Este artigo apresenta a proposta temática do curso de Aperfeiçoamento em Saúde Mental da Universidade Federal de São Paulo (Unifesp) e discute suas estratégias conceituais no âmbito da formação permanente e da implementação de ações de Saúde Mental na Rede de Atenção Psicossocial. O curso buscou promover a compreensão do sofrimento e as dimensões cotidianas que são afetadas na vida da pessoa como abertura e aproximação para as ações de saúde mental em diálogo com a proposta de construção de um novo objeto para intervenções em saúde mental no contexto da Reforma Psiquiátrica. Ofereceu também a possibilidade de trabalho em rede a partir de ações territoriais alicerçadas nesse modo de compreender o objeto da saúde mental. No fim dessa experiência, pôde-se reconhecer que ocorreu maior envolvimento e situações de encontros entre trabalhadores de diferentes pontos da rede e entre trabalhadores e usuários.

Palavras-chave: Sofrimento psíquico. Educação permanente. Reforma psiquiátrica. Rede de atenção psicossocial.

\section{The challenge of continuing education in the strengthening of Psychological Care Networks}

This article presents the thematic proposal of the mental Health Graduate Course of the Federal University of São Paulo, and discusses its conceptual strategies in the scope of continuing education and the implementation of actions in Mental Health in the Psychosocial Care Network. The aim of the course was to promote the understanding of suffering and the daily dimensions that are affected in people's life as a starting point for mental health actions in dialogue with the proposal of building a new object for mental health interventions in the context of the Psychiatric Reform. It also provided the possibility of working in a network based on territorial actions grounded on this way of understanding the mental health object. At the end of this experience, it was possible to recognize greater involvement and situations of encounter between users and workers from different points in the network.

Keywords: Psychological stress. Continuing education. Psychiatric reform. Psychosocial care network.

\section{El desafío de la formación permanente en el fortalecimiento de las Redes de Atención Psicosocial}

Este artículo presenta la propuesta temática del curso de Perfeccionamiento en Salud Mental de la Universidad Federal de São Paulo y discute sus estrategias conceptuales en el ámbito de la formación permanente y de la implementación de acciones de salud mental en la Red de Atención Psicosocial. El objetivo del curso fue promover la comprensión del sufrimiento y las dimensiones cotidianas afectadas en la vida de la persona como apertura y aproximación para las acciones de salud mental en diálogo con la propuesta de construcción de un nuevo objeto para intervenciones en salud mental en el contexto de la Reforma Psiquiátrica. También ofreció la posibilidad de trabajo en red a partir de acciones territoriales fundamentadas en ese modo de comprender el objeto de la salud mental. Al final de esa experiencia fue posible reconocer que hubo mayor envolvimiento y situaciones de encuentros entre trabajadores de diferentes puntos de la red, entre trabajadores y usuarios.

Palabras clave: Sufrimiento psíquico. Educación permanente. Reforma psiquiátrica. Red de atención psicosocial. 